\title{
Correction to: Research on Fuzzy Energy Control Strategy for Four-Wheel Hybrid Electric Vehicle
}

Cheng Li, Xu Wang, Zhongwen Zhu, and Qing Wei

\section{Correction to:}

Chapter "Research on Fuzzy Energy Control Strategy

for Four-Wheel Hybrid Electric Vehicle" in:

China Society of Automotive Engineers (ed.), Proceedings of China SAE Congress 2019: Selected Papers, Lecture Notes in Electrical Engineering 646, https://doi.org/10.1007/978-981-15-7945-5_80

In the original version of the book, the following correction has been incorporated: The title of Chapter 80 has been changed from "Research on Fuzzy Energy Control Strategy for Four-Wheel Hubrid Elestric Vehicle" to "Research on Fuzzy Energy Control Strategy for Four-Wheel Hybrid Electric Vehicle". The book and the chapter have been updated with the changes. 